\title{
The characteristics and expression profiles of the mitochondrial genome for the Mediterranean species of the Bemisia tabaci complex
}

\author{
Hua-Ling Wang ${ }^{1}$, Jiao Yang ${ }^{1}$, Laura M Boykin², Qiong-Yi Zhao ${ }^{3}$, Qian Li ${ }^{1}$, Xiao-Wei Wang ${ }^{1 *}$ and Shu-Sheng Liu ${ }^{1 *}$
}

\begin{abstract}
Background: The whiteflies under the name Bemisia tabaci (Gennadius) (Aleyrodidae: Hemiptera) are species complex of at least 31 cryptic species some of which are globally invasive agricultural pests. Previously, the mitochondrial genome (mitogenome) of the indigenous New World B. tabaci species was sequenced and major differences of gene order from the postulated whitefly ancestral gene order were found. However, the sequence and gene order of mitogenomes in other B. tabaci species are unknown. In addition, the sequence divergences and gene expression profiles of mitogenomes in the $B$. tabaci species complex remain completely unexplored.

Results: In this study, we obtained the complete mitogenome (15,632 bp) of the invasive Mediterranean (MED), which has been identified as the type species of the B. tabaci complex. It encodes 37 genes, including 13 proteincoding genes (PCGs), 2 ribosomal RNAs and 22 transfer RNAs (tRNA). Comparative analyses of the mitogenomes from MED and New World (previously published) species reveal that there are no gene arrangements. Based on the Illumina sequencing data, the gene expression profile of the MED mitogenome was analyzed. We found that a number of genes were polyadenylated and the partial stop codons in cox1, cox2 and nd5 are completed via polyadenylation that changed T to the TAA stop codon. In addition, combining the transcriptome with the sequence alignment data, the possible termination site of some PCGs were defined. Our analyses also revealed that atp6 and atp8, nd4 and nd4I, nd6 and cytb were found on the same cistronic transcripts, whereas the other mature mitochondrial transcripts were monocistronic. Furthermore, RT-PCR analyses of the mitochondrial PCGs expression in different developmental stages revealed that the expression level of individual mitochondrial genes varied in each developmental stage of nymph, pupa and adult. Interestingly, mRNA levels showed significant differences among genes located in the same transcription unit suggesting that mitochondrial mRNA abundance is heavily modulated by post-transcriptional regulation.
\end{abstract}

Conclusions: This work provides novel insights into the mitogenome evolution of B. tabaci species and demonstrates that utilizing RNA-seq data to obtain the mitogenome and analyze mitochondrial gene expression characteristics is practical.

Keywords: Bemisia tabaci, Gene expression, Mediterranean, Mitochondrial genome, Mitogenomics, Whitefly

\footnotetext{
* Correspondence: xwwang@zju.edu.cn; shshliu@zju.edu.cn

'Ministry of Agriculture Key Laboratory of Agricultural Entomology, Institute

of Insect Sciences, Zhejiang University, Hangzhou 310058, China

Full list of author information is available at the end of the article
} 


\section{Background}

Bemisia tabaci, the sweet potato whitefly, causes millions of dollars of crop damage globally $[1,2]$ and is considered one of the world's top 100 invasive species according to the International Union for the Conservation of Nature and Natural Resources (IUCN) (http://www.issg.org). It is capable of causing extensive damage to major vegetable, grain legume and fiber crops and regarded as a regulated species by a number of countries or regions, e.g., Australia, Africa, China, the EU, and the USA. There are two main types of damage caused by $B$. tabaci; the first is caused by immature and adult stages feeding (they ingest phloem sap and this causes damage). The second type is indirect damage from excretion of honeydew onto the surfaces of leaves and fruit and this promotes the growth of sooty mold fungi which uses honey dew as a substrate and colonizes contaminated surfaces, further interfering with photosynthesis, ultimately resulting in reduced quality of fruit and fiber [3]. In addition, B. tabaci is the vector of many economically important plant viral-pathogens, most being begomoviruses (Geminiviridae); a group recognized as the most important emerging plant virus group in subtropical and tropical world regions [4-6].

B. tabaci is now known as a species complex with dozens of morphologically indistinguishable species and contains both invasive and native members [7-10]. In 2007, the first global mitochondrial cytochrome oxidase I (mtCOI) dataset for B. tabaci was used to reconstruct the global phylogenetic relationships, indicating significant variation between and within genetic groups [11]. Since that pivotal work in 2007, B. tabaci has been shown to be a species complex with at least 31 distinct genetic groups identified based on mtCOI [7,8,10-12]. What is more, by matching museum syntypes from the 1889 original specimen from Gennadius using mtCOI molecular maker, MED were recognized as the type species of the B. tabaci complex [13]. With the taxonomy of the B. tabaci species complex becoming clearer, it is now possible to use this information to carry out detailed comparative studies. This includes uncovering and comparing the mitochondrial genomes (mitogenomes) of the different species in the B. tabaci complex. Thao et al. (2004) sequenced the mitogenomes of six whitefly species and found that four of them had an rearrangement of the cox 3 - nd3 region compared to the hypothesized ancestral insect mitochondrial gene order [14]. They suggest, based on this rearrangement that this region has been transposed, at least four times in the evolution of whiteflies. However, whether the gene order of mitogenome in other B. tabaci species, especially the invasive MED and MEAM1, differs from the ancestral whitefly mitogenome is still unknown. Furthermore, in the B. tabaci species complex, only the mitogenome of New World species is available [14], a detailed comparison of mitogenomes between members of the $B$. tabaci species complex is still lacking. In this study, we decided to explore variation in the mitogenomes of the B. tabaci species complex. This study will also add to the growing literature on insect comparative mitogenomics of closely related species [15-20].

In addition to using the mitogenome for evolutionary study, we are also interested in the function of the mitochondrial genes. The mitochondrion is an important organelle responsible for numerous important cellular functions in insects such as energy transduction, apoptosis, detoxification, signal transduction and ATP production $[21,22]$. With few exceptions, insect mitogenomes contain 37 genes encoding 13 protein coding genes (PCGs), 2 ribosomal RNAs ( $r r n L$ and $r r n S$ ) and 22 transfer RNAs (tRNAs) [24]. The gene organization of mitogenomes is different between insects $[25,26]$ and mechanisms of mitochondrial gene expression have been investigated in various organisms [27-29]. Studying the mitochondrial gene organization and expression may facilitate the elucidation of mitogenome evolution and characterization of key components regulating insect biology [23]. At present, large amount of information about mitochondrial expression profile has focused on studies of humans, mice or Drosophila [30]. Relatively little is known about the features of non-model insect mitogenomes, such as polyadenylation and modes of gene transcription [28,31-33].

Next-generation sequencing (NGS) data is important to predict processed mitochondrial transcripts and reveal transcription process in mitogenomes [21,34,35]. For example, the transcription profile of genes encoded in the mitogenome of Drosophila and the legume pod borer Maruca vitrata has been revealed using NGS data $[21,34]$. For B. tabaci, the transcriptome of MED has been sequenced and a total of 43 million reads were obtained [36]. A large number of sequencing reads could be mapped to the mitogenome of the New World B. tabaci species (data not shown). Therefore, a second goal of this study is to utilize NGS data to analyzing the characteristics of whitefly mitochondrial gene expression, including the translation start site of PCGs, polyadenylation and polycistronic transcripts.

\section{Results}

Obtaining the MED mitogenome sequences with the NGS data

Without prior amplification of specific regions of the mitogenome, DNA sequence data obtained by NGS methodology can generate sequences of the mitogenome [35]. In this study, 43 million Illumina sequencing reads of MED [36] were used to retrieve the MED mitogenome sequences by mapping them to the available mitogenome of B. tabaci New World species (GenBank accession number: AY521259). A total of 635,172 reads were mapped to 
the New World species reference mitogenome. These reads were assembled into eight contigs distributed in different parts of the New World mitogenome (Additional file 1). The missing base positions were 1-104, 624-800, 2042-2211, 2237-2282, 7523-7595, 11209-11434, 1153711614 and 13566-13762. Specific primers were then designed to close these gaps (Additional file 2).

\section{The MED mitogenome}

The complete mitogenome of MED is 15,632 bp and encodes the 37 genes (13 PCGs, 22 tRNA and 2 rRNA genes), found in most metazoan mitogenomes (Figure 1 and Table 1) [37]. The MED mitogenome also includes 10 non-coding portions (intergenic spacers), which are at least 10 bps long. Two pairs of genes (atp6 and atp 8 ; $n d 4$ and $n d 4 l$ ) are located on the same strand and overlap by $10 \mathrm{bp}$ and $3 \mathrm{bp}$, respectively, which is a common feature of insect mitochondrial DNA [31,32]. The other genes are contiguous or separated by a few nucleotides or intergenic spacers (Figure 1). The entire complement of 22 tRNAs ranging in size from 63 to 78 bp was found and most of the tRNAs can be folded as classic cloverleaf structures except tRNA-SerUCU that is missing the dihydorouridine (DHU) arm as in most metazoan. Compared to the New World mitogenome (15,332 bp), there is a slight expansion of MED (15,632 bp) due to an insertion of repeat sequences in the A + T-rich region. In addition, the mitogenome of MED has the same gene order as that of New World species, which differs from the gene order of postulated whitefly ancestor [14].

\section{Sequence divergence between mitogenoms of the MED and New World B. tabaci species}

An earlier study of the whitefly mitogenomes focused on the gene arrangement in the New World species [29]. To understand the divergence and evolution of $B$. tabaci mitogenomes, the differences between MED and New World mitogenomes (GenBank accession number: AY521259) were analyzed in detail. For the 13 PCGs, the overall divergence between MED and New World is $21.30 \%$, which is higher than the divergence of $\operatorname{cox} 1$ sequences (14.9\%) which was used to define the B. tabaci species limits [12]. The nucleotide sites in PCGs were further classified into nondegenerate (nd) (any nucleotide substitutions produce amino acid change) and fourfold degenerate sites (4d) (no changes cause amino acid

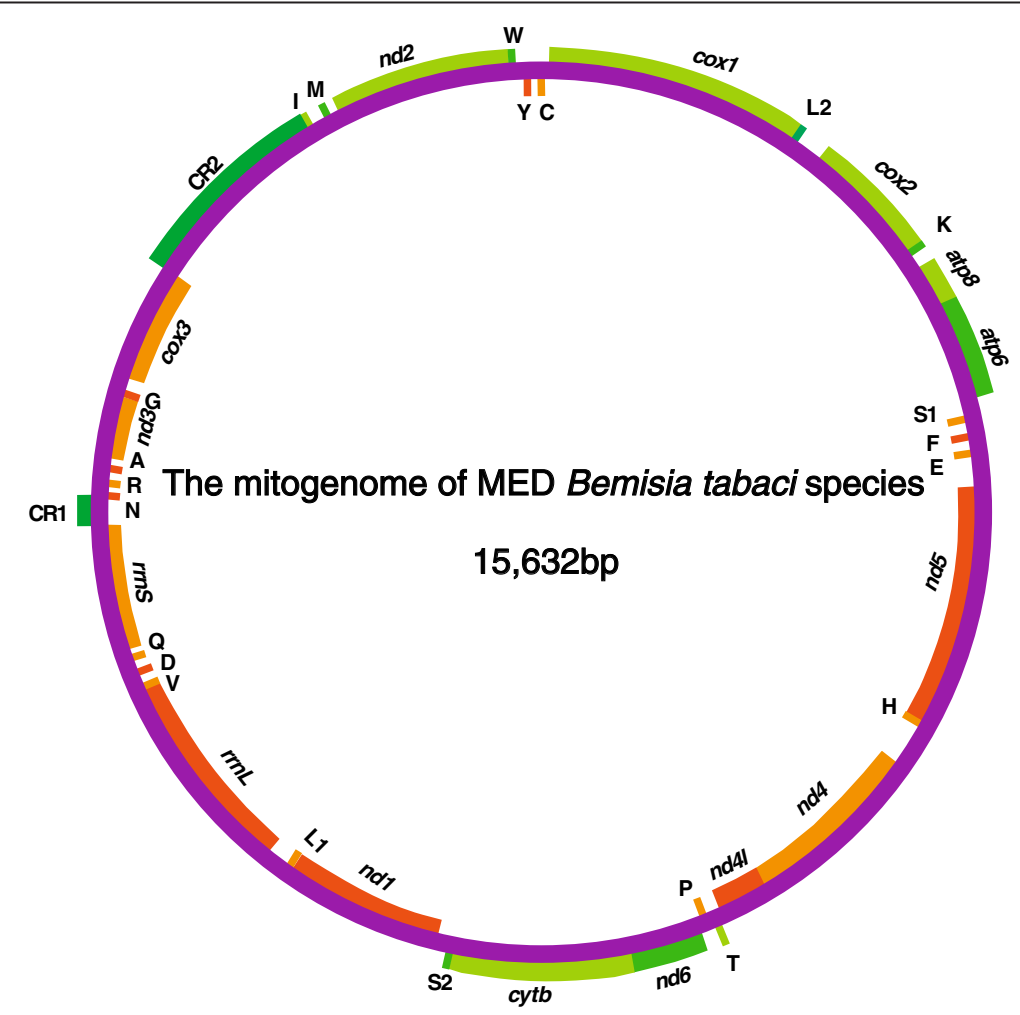

Figure 1 The mitogenome of the MED species. Genes coded in the N strand (clockwise orientation) are pine and cypress green or bean green colored. Genes coded in the J strand (anti-clockwise orientation) are tangerine or bright yellow colored. CR1, CR2 represent control regions. tRNAone letter amino acid abbreviation (parenthesis three letter amino acid abbreviation followed by anticodons): tRNA-A (ala), tRNA-C (cys), tRNA-D (asp), tRNA-E (glu), tRNA-F (phe), tRNA-G (gly), tRNA-H (his), tRNA-I (ile); tRNA-K (lys), tRNA-L1 (leu), tRNA-L2 (leu), tRNA-M (met), tRNA-N (asn), tRNA-P (pro), tRNA-Q (gln), tRNA-R (arg), tRNA-S1 (ser), tRNA-S2 (ser), tRNA-T (thr), tRNA-V (val), tRNA-W (trp), and tRNA-Y (tyr). CR1: the first putative control region; CR2: the second putative control region. 
Table 1 Mitochondrial genes of MED as determined by DOGMA

\begin{tabular}{|c|c|c|c|c|c|c|}
\hline Gene & Strand & From & To & Length (bp) & Start & Stop \\
\hline $\operatorname{cox} 1$ & + & 1 & 1537 & 1537 & ATG & $T$ \\
\hline tRNA-LeUUUR & + & 1538 & 1602 & 65 & & \\
\hline $\cos 2$ & + & 1603 & 2266 & 664 & ATA & $\mathrm{T}$ \\
\hline tRNA-LysAAR & + & 2267 & 2334 & 68 & & \\
\hline atp8 & + & 2360 & 2593 & 234 & ATG & TAG \\
\hline atp6 & + & 2583 & 3233 & 651 & ATG & TAA \\
\hline tRNA-SerUCN & - & 3278 & 3334 & 57 & & \\
\hline tRNA-GluGAR & - & 3345 & 3407 & 63 & & \\
\hline tRNA-PheUUY & - & 3423 & 3489 & 67 & & \\
\hline nd5 & - & 3490 & 5143 & 1654 & ATT & $\mathrm{T}$ \\
\hline tRNA-HisCAY & - & 5141 & 5205 & 65 & & \\
\hline nd4 & - & 5206 & 6498 & 1293 & ATA & TAA \\
\hline$n d 4 l$ & - & 6495 & 6779 & 285 & ATG & TAA \\
\hline tRNA-ThrACN & + & 6781 & 6858 & 78 & & \\
\hline tRNA-ProCCN & - & 6847 & 6908 & 62 & & \\
\hline nd6 & + & 6943 & 7389 & 547 & ATG & TAA \\
\hline cytb & + & 7388 & 8524 & 1137 & ATG & TAA \\
\hline tRNA-SerAGY & + & 8520 & 8583 & 64 & & \\
\hline ndl & - & 8582 & 9517 & 936 & ATT & TAA \\
\hline tRNA-LeuCUN & - & 9518 & 9585 & 68 & & \\
\hline$r r n L$ & - & 9585 & 10795 & 1211 & & \\
\hline tRNA-ValGUN & - & 10796 & 10863 & 68 & & \\
\hline tRNA-AspGAY & - & 10867 & 10938 & 72 & & \\
\hline tRNA-GInCAR & - & 10944 & 11007 & 64 & & \\
\hline$r r n s$ & - & 11017 & 11687 & 671 & & \\
\hline tRNA-AsnAAY & - & 11917 & 11980 & 64 & & \\
\hline tRNA-ArgCGN & - & 11981 & 12049 & 69 & & \\
\hline tRNA-AlaGCN & - & 12053 & 12117 & 65 & & \\
\hline nd3 & - & 12123 & 12476 & 354 & ATG & TAA \\
\hline tRNA-GlyGGN & - & 12478 & 12540 & 63 & & \\
\hline $\cos 3$ & - & 12569 & 13354 & 786 & ATT & TAG \\
\hline tRNA-IleAUN & + & 14328 & 14396 & 65 & & \\
\hline tRNA-MetAUG & + & 14395 & 14462 & 68 & & \\
\hline$n d 2$ & + & 14478 & 15431 & 954 & ATC & TAA \\
\hline tRNA-TrpUGG & + & 15430 & 15497 & 68 & & \\
\hline tRNA-TyrUAY & - & 15496 & 15558 & 63 & & \\
\hline tRNA-CysUGY & - & 15557 & 15630 & 74 & & \\
\hline
\end{tabular}

replacement). The 4d sites within PCGs are free from selective constraints and can provide data for inferring evolutionary distance [38]. From a total of 10,941 bp of PCGs, 6,150 bp are nd sites, whereas 1,070 bp are 4d sites (Table 2). At $4 \mathrm{~d}$ sites the overall divergence is $39.95 \%$, whereas the overall divergence at nd sites is only $9.96 \%$.
Table 2 Sequence divergence of mitogenome between the invasive MED and New World cryptic species

\begin{tabular}{|c|c|c|c|c|c|c|c|}
\hline & $\%$ CpG & $\% G C$ & Loci & $\begin{array}{l}\% \text { mean of } \\
\text { difference }\end{array}$ & SE & Compared kb & $\mathrm{Ts} / \mathrm{Tv}^{\mathrm{d}}$ \\
\hline $\mathrm{CDS}^{\mathrm{a}}$ & 2.6 & 26 & 13 & & & & \\
\hline All & & & & 21.30 & 0.014 & 10.94 & 1.72 \\
\hline $\begin{array}{l}\mathrm{No} \\
\mathrm{CpG}\end{array}$ & & & & 20.88 & 0.014 & 10.66 & 1.69 \\
\hline CpG & & & & 36.21 & 0.040 & 0.28 & 2.38 \\
\hline $\begin{array}{l}\text { nd } \\
\text { sites }^{b}\end{array}$ & 2.83 & 29.89 & 13 & & & & \\
\hline All & & & & 9.96 & 0.012 & 6.15 & 1.52 \\
\hline $\begin{array}{l}\mathrm{No} \\
\mathrm{CpG}\end{array}$ & & & & 9.99 & 0.012 & 5.98 & 1.46 \\
\hline CpG & & & & 9.87 & 0.037 & 0.17 & 13.00 \\
\hline $\begin{array}{l}4 d \\
\text { sites }^{c}\end{array}$ & 6.36 & 19.46 & 13 & & & & \\
\hline All & & & & 39.55 & 0.031 & 1.07 & 0.85 \\
\hline $\begin{array}{l}\mathrm{No} \\
\mathrm{CpG}\end{array}$ & & & & 37.09 & 0.029 & 1.00 & 0.81 \\
\hline $\mathrm{CpG}$ & & & & 80.03 & 0.086 & 0.07 & 1.14 \\
\hline
\end{tabular}

At nd sites, the divergence at non-CpG sites and $\mathrm{CpG}$ sites are comparable between mitogenomes of the MED and New World species. However, at $4 \mathrm{~d}$ sites, the divergence of CpG sites (80.03\%) is 2 times of that at the nonCpG sites (37.09\%). These results demonstrate that the higher percentage of divergence at the $4 \mathrm{~d}$ sites is proportional to both the content of $\mathrm{CpG}$ sites and the rate of mutation (Table 2).

The value of $\mathrm{Ka} / \mathrm{Ks}$ ratios can be used as an indicator of selective pressure acting on a PCG [39]. To infer the direction and magnitude of natural selection acting on PCGs, the rate of non-synonymous substitutions (Ka), synonymous substitutions (Ks) and the ratio of $\mathrm{Ka} / \mathrm{Ks}$ were estimated for each PCG between the MED and New World mitogenomes (Figure 2). Among the 13 pairs of PCGs, the Ka/Ks ratio of atp 8 was the highest (0.696), indicating that atp 8 has been evolving under high selection pressure and has the potential value for studying the inherit diversity of different $B$. tabaci populations within a species [40,41]. Cox1, cox2, atp6, cytb, cox3 and $n d 3$ showed the lowest $\mathrm{Ka} / \mathrm{Ks}$ values (below 0.1 ), suggesting that those genes are under high purifying selection.

\section{Codon usage}

The four most frequently used codons were UUU-F (418), UUA-L (394), AUU-I (298) and UAU-Y (262) (Additional file 3) in MED species, while in the New 


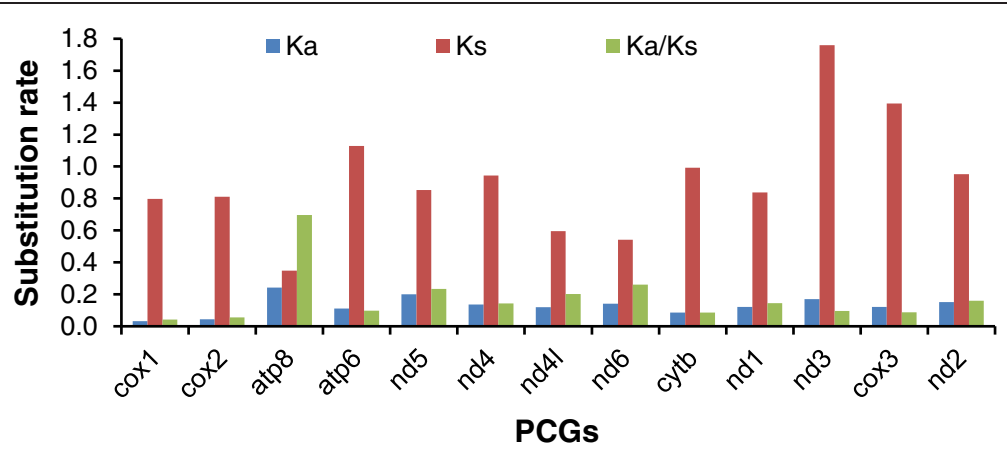

Figure 2 Evolutionary rates of PCGs between MED and New World mitogenomes. Ka: nonsynonymous substitution rate;Ks: synonymous substitution rate. The histogram represented the value of Ka, Ks and Ka/Ks for each PCG.

World were UUU-F (404), UUA-L (316), AUU-I (306) and AAU-N (306) (Additional file 4). To compare the usage of start and stop codons in species closely related to $B$. tabaci, nine species (including seven species of whiteflies, 1 psyllid and 1 aphid) within the suborder Sternorrhyncha (Hemiptera) were used [42]. Results show that start codons (Additional file 5) and stop codons (Additional file 6) are used at different frequencies (Figure 3A \& 3B). Incomplete stop codons have previously been found in insect mitogenomes and are common in metazoans [37]. In the process of posttranscriptional modification, the incomplete stop codon is polyadenylated to complete poly(A) tail and changed $\mathrm{T}$ or TA to the TAA stop codon [43]. In the MED mitogenome, complete translation termination codons were used by ten genes, excluding $\operatorname{cox} 1, \operatorname{cox} 2$ and $n d 5$, which have incomplete stop codons [24,44-46]. These three genes also used the incomplete $\mathrm{T}$ stop codon in the New World species. But in other seven species, incomplete stop codons were also used by different genes (Additional file 6).

\section{Control regions}

Using long-PCR, two large non-coding regions were recovered from the MED mitogenome, which was called putative control regions because of the following reasons. First, these two large non-coding regions can form stemloop structures, which typically associated with the origins of replication/transcription. Second, elements related to transcription and DNA replication were found in both regions. Third, New World B. tabaci was shown to have two control regions (one small and one large) [47]. Sequence analyses revealed that the two putative control regions were located in the same region in the mitogenomes of MED and New World species. In both species, one of the putative control regions was located between $r r n S$ and $t r n N$, while the other located between cox3 and trnI (Figure 1). By analyzing these two areas, elements proposed to be involved in mitogenome replication and gene transcription were found in both control regions (Figure 4). In the first putative control region, both the MED and New World mitogenomes have the same five elements: polyT stretch, $\mathrm{A}[\mathrm{TA}(\mathrm{A})]_{\mathrm{n}}$-like stretch, TATA motif, stem and loop structure and $G[A]_{n} T$

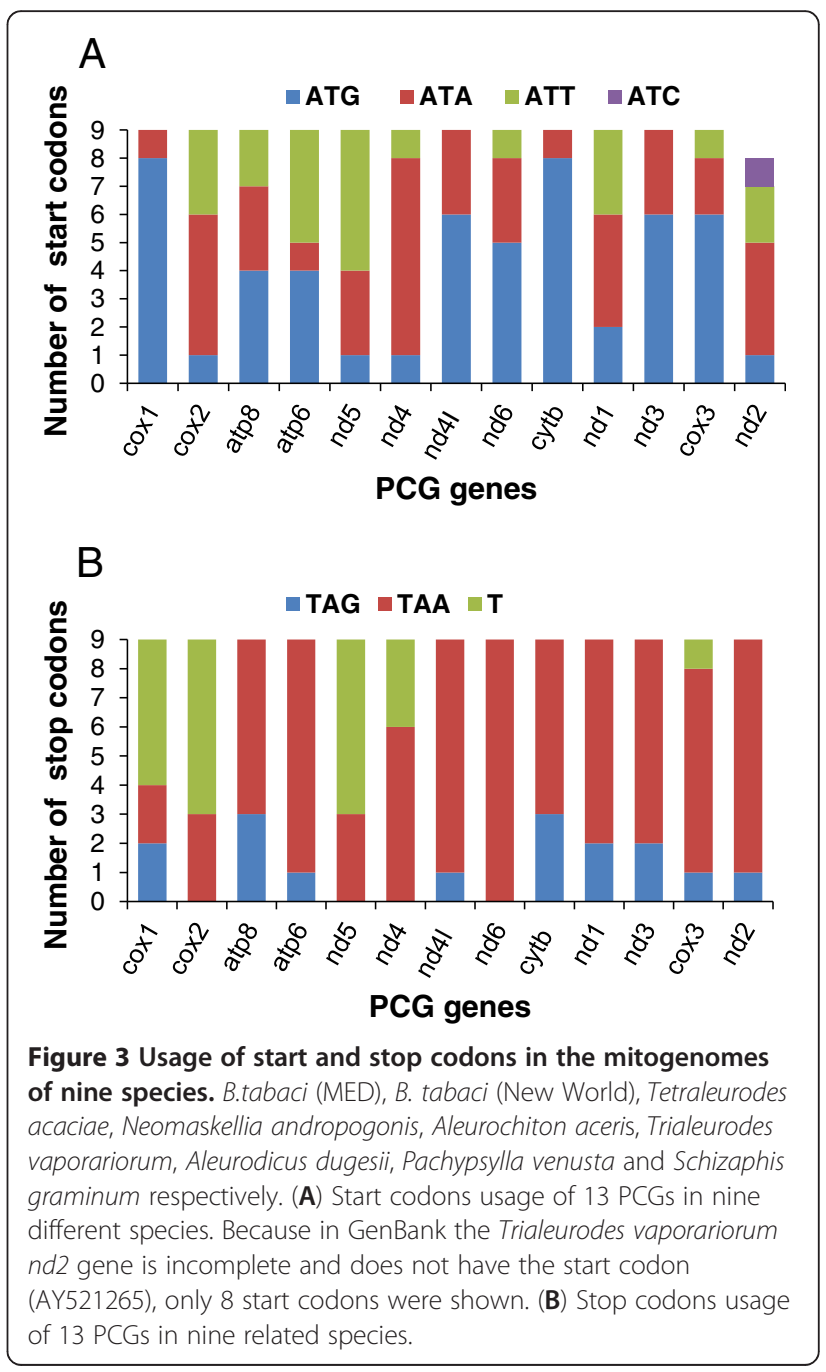




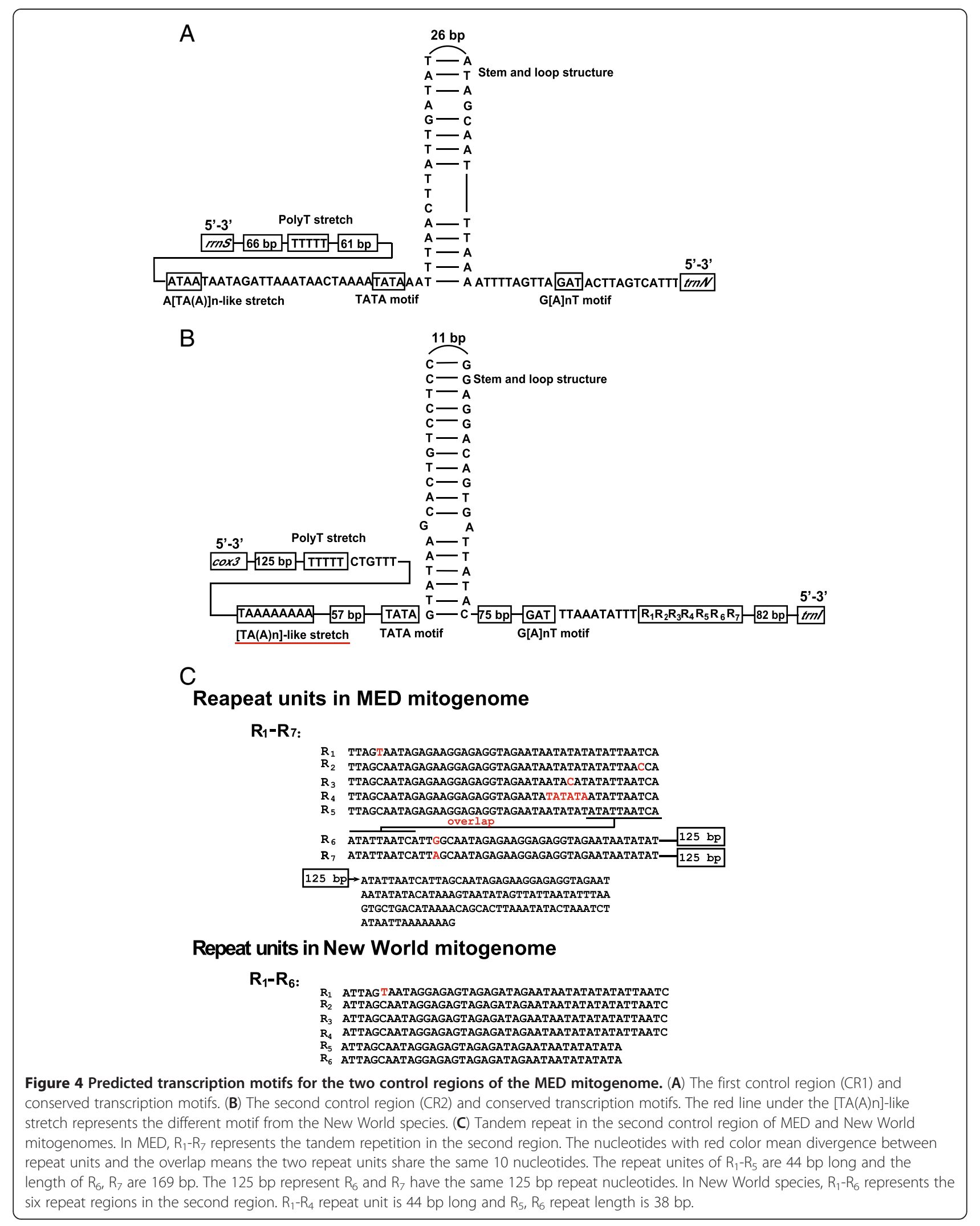


motif (Figure 4A). However, in the second putative control region, the sequence of the transcription elements and the tandem repeat regions are different [47]. In the second putative control region of the MED mitogenome, the $[\mathrm{TA}(\mathrm{A}) \mathrm{n}]$-like stretch differs from the A[TA(A)]n-like stretch in that of New World (Figure 4B). In addition, seven repeat units are found in the second control region of the MED mitogenome. Repeat units of $R_{1}-R_{5}$ are $44 \mathrm{bp}$ long and the length of $R_{6}, R_{7}$ is $169 \mathrm{bp}$ (Figure 4C). However, the second putative control region of the New World mitogenome contains 6 repeat unites, in which the $R_{1}-R_{4}$ repeat units are 44 bp long and the $R_{5}, R_{6}$ repeats are 38 bp (Figure 4C).

\section{Transcript reads mapping to the MED mitogenome}

NGS technologies have been applied to analyze the gene expression profile of mitochondrial-derived transcripts [21,33]. Previously, we have sequenced the transcriptome of MED and obtained 43 million 75 bp reads [36]. In this study, those sequencing reads were mapped onto the complete MED mitogenome and the numbers of reads per base calculated (read coverage). Based on the mapped reads, we analyzed the reads depth for every base of the MED mitogenome and found that the expression levels of individual mitochondrial genes (13 PCGs and 2 rRNAs) varied greatly from 21 to 236,749 reads per base (Additional file 7). For all coding regions, $r r n L$ had the highest expression level, while $n d 4 l$ the lowest. This result is similar to the findings in Drosophila melanogaster and the pod borer Maruca vitrata [21,33]. The expression level of other PCGs, from highest to lowest, were $\operatorname{cox} 2, \operatorname{cox} 1, \operatorname{atp} 8, n d 1$, cox3, cytb, atp6, nd4, nd5, nd2, rrnS, nd3 and nd6. Such differences suggest that the expression profile of mitochondrial genes is highly variable (Figure 5) [35].

\section{Reads mapped to tRNAs and control regions}

Reads mapped to tRNA, PCGs and control regions can reveal different features for each of the segments. In the MED mitogenome, the read coverage of tRNAs was relatively low compared to that of PCGs and no reads were recovered for some of tRNAs. In addition, a number of reads were mapped to putative control regions, indicating the existence of non-coding RNA (ncRNA). The expression levels for the first and the second control regions were 0.44 and 90.93 , respectively, suggesting that the two putative control regions were transcribed at different levels. However, both functional and comparative studies are needed to examine whether these two putative control regions are real control regions $[48,49]$. In addition, some reads were also mapped to the intragenic spacer region and the expression level varied (Figure 5). These results suggest that while the control and intervening spacer regions are transcribed, their expression levels are lower than that of PCGs. Interestingly, the same phenomenon has been found in the mitogenomes of mouse, pig and salamander [33,50]. The latest research also revealed that the mammalian mitogenomes encode abundant ncRNAs besides the 37 known mitochondrial genes [51]. Whether these ncRNAs may play a role in posttranscriptional processing or simply reflect polycistronic transcription warrants further investigation.

\section{Polyadenylation of mitochondrial PCGs}

The polyadenylation of mRNAs plays critical roles in regulating gene expression, complementing coding information and determining gene boundaries [52]. To characterize the polyadenylation of MED mitochondrial genes, sequencing reads mapped to the MED mitogenome and having poly(A) stretches at the 3' end were analyzed

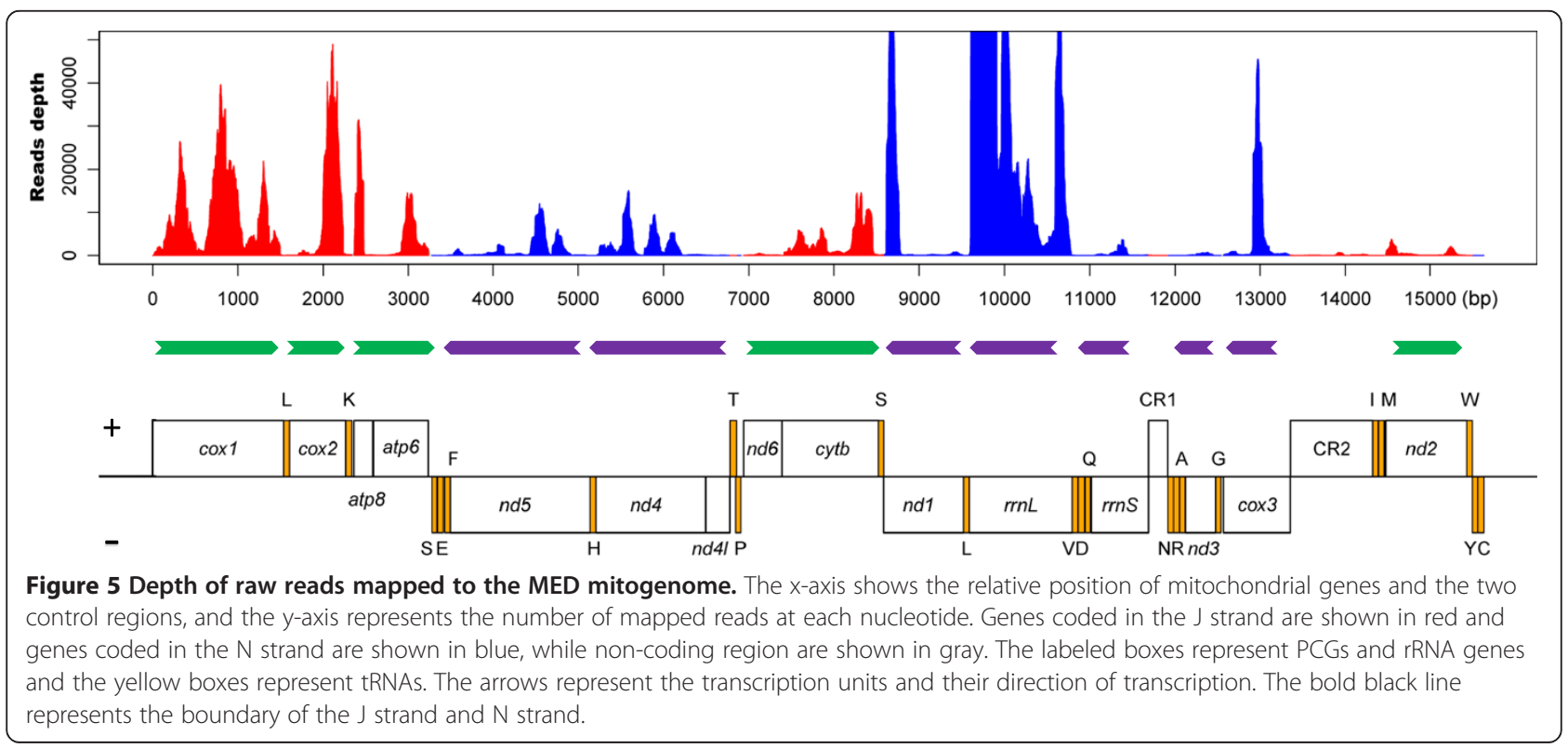


further. Interestingly, a number of reads with poly(A) stretches were mapped at the end or downstream of the stop codons of cox1, cox2, nd3, nd4, nd5, nd6 and cytb genes (Figure 6). In addition, poly(A) tail was found in the downstream of $\operatorname{lrRNA}$ and srRNA too. Similar to the results found in Drosophila [27], the partial stop codon in $\operatorname{cox} 1, \operatorname{cox} 2$ and $n d 5$ is completed via polyadenylation that changed $\mathrm{T}$ to the TAA stop codon. Poly(A) signals are a common feature of eukaryotic PCGs [53]. From the reads mapped to the 3' end of PCGs, some possible poly(A) signals were recognized (Figure 6). Furthermore, as the sequencing reads are only $75 \mathrm{bp}$, some poly(A) signals were found in the upstream mitochondrial DNA sequence. All of those poly(A) signals were recognized 8-229 bp up- stream of the poly(A) tail. In the 7 PCGs with poly(A) tails, different poly(A) signals were found (Figure 6). These findings confirm that whitefly mitochondrial mRNAs possess poly(A) tail and 3' proximal poly(A) signals. In addition, these polyadenylation information was employed to annotate the exact termination site of PCGs [27]. Indeed, the location of poly(A) in the 7 PCGs supports the termination site of PCGs predicted via homologous annotation (data not shown).

\section{MED mitochondrial polycistronic transcripts}

Generation of polycistronic transcripts is a distinct feature of many mitogenomes, and the co-transcription of genes may be used for regulation of gene expression

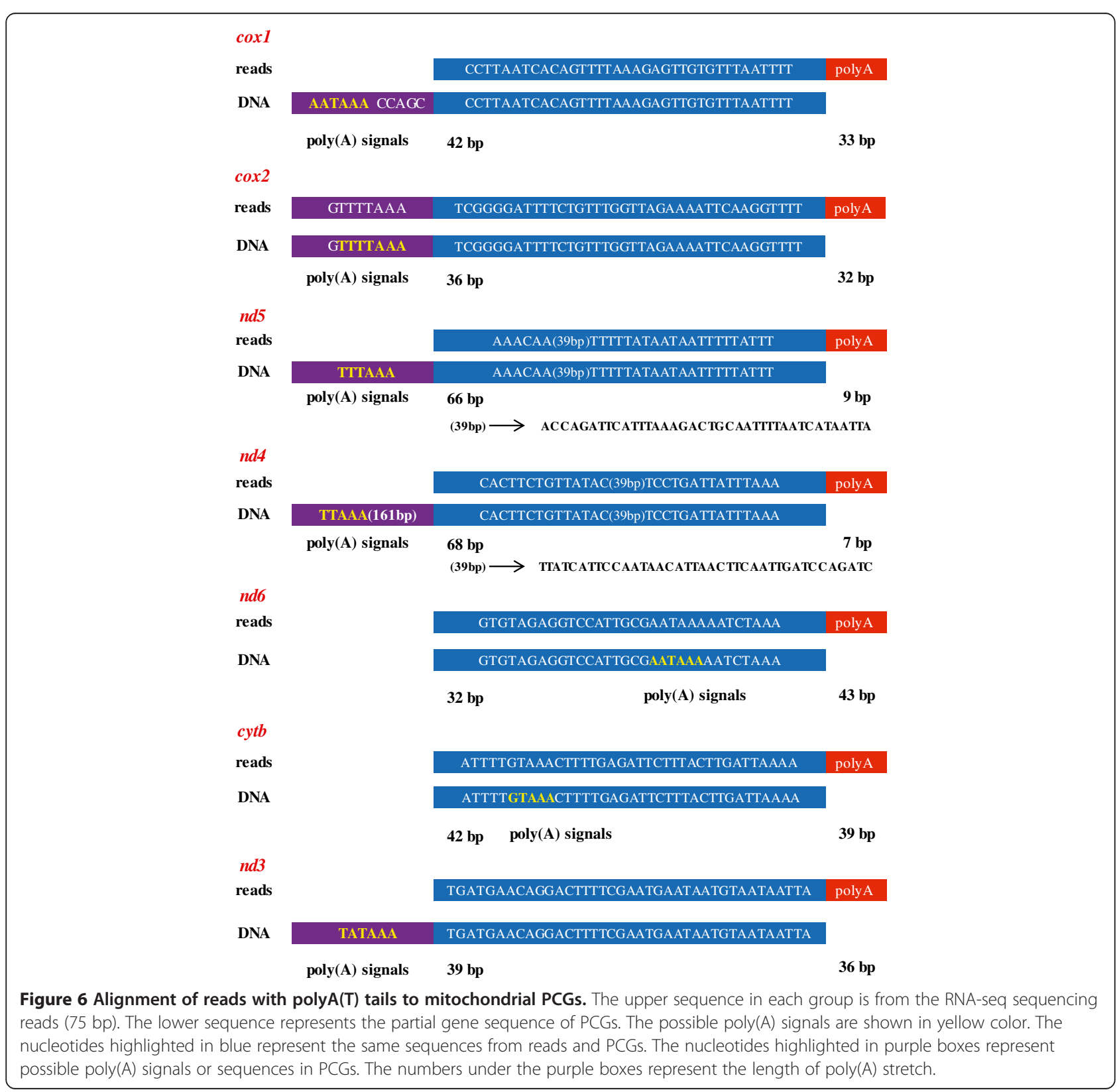


[54]. Two genes on the same mature polycistronic transcripts had been reported in the dipteran insects $D$. melanogaster, D. pseudoobscura and lepidopteran insect M. vitrata $[21,33]$. To detect possible mature dicistronic transcripts, the assembled MED transcriptome sequences were mapped to the MED mitogenome. Interestingly the atp6 and atp 8 genes, $n d 4 l$ and $n d 4$ genes, and nd6 and cytb genes were found in the same contigs respectively (Table 3 ). The assembled contigs may represent mature transcripts that are generated from tRNA punctuated cleavage of polycistronic transcripts [43,55]. In addition, we can clearly find dip in expression levels associated with the ends of these genes (atp8-atp6, nd4l$n d 4$ and nd6-cytb) (Figure 5). This is consistent with a mature dicistronic mRNA. By default, if the mitochondrial genes are contiguous within the genome and lack of intervening tRNA, they are transcribed on the same cistrons. Similarly, atp6 and atp8, nd4l and nd4, and $n d 6$ and $c y t b$ genes are contiguous within the mitogenome and also exist in the same contigs.

\section{Single nucleotide polymorphism (SNP) in the MED mitogenome}

SNPs might be useful for discovering genes under selection and the dynamics of these genes in natural populations [56]. Therefore SNPs in the MED mitogenome were investigated using the 43 million Illumina sequencing reads and only 8 SNPs were discovered (Table 4). Among the 8 SNPs, 5 were found in the coding region and 3 were observed in the control region. Interestingly, all the 5 SNPs in the coding region ( $\operatorname{cox} 1, \operatorname{cox} 2$, nd5, $c y t b, n d 2)$ were $\mathrm{C} / \mathrm{G}$ to A/T mutation; and only 2 SNPs in the gene of $\operatorname{cox} 2, n d 5$ lead to the amino acid changes. As the whitefly specimens used for RNA-Seq was derived from a laboratory colony, it is possible few SNPs were identified due to clonality. For practical purposes,

Table 3 The expression profile of contigs transcribed from the MED mitogenome

\begin{tabular}{lll}
\hline Contigs & Genes within contig & Contig length (bp) \\
\hline > comp32_c0_seq1 & atp8, atp6 & 851 \\
> comp50_c0_seq1 & nd5 & 1480 \\
> comp29_c0_seq2 & nd4 & 1081 \\
> comp1997_c0_seq1 & nd4, nd4l & 557 \\
> comp34_c0_seq1 & nd6, cytb & 1636 \\
> comp4_c0_seq1 & nd1 & 546 \\
> comp984_c0_seq1 & nd3 & 468 \\
> comp6_c0_seq1 & cox3 & 881 \\
> comp249_c0_seq1 & nd2 & 1077 \\
> comp0_c0_seq1 & rrnL & 674 \\
> comp252_c0_seq2 & rrns & 784 \\
\hline
\end{tabular}

field-collected whitefly populations, or species that had undergone different lab selections, regimes should be used to identify SNPs.

\section{Detecting PCG gene expression in different developmental stages}

The mitogenome encodes proteins in the electron transport chain including NADH dehydrogenase (complex I), Cytochrome b (complex III), and Cytochrome c oxidase (complex IV) and ATP synthase $\left(\mathrm{F}_{0} \mathrm{~F}_{1}\right.$-complex). These proteins play important roles in oxidative phosphorylation and ATP generation. Many studies have shown different gene expression profiles of PCGs at different developmental stages [57-60]. However, the expression profile of mitochondrial genes at different developmental stages is poorly understood. Using RT-PCR, the expression level of 11 PCGs was detected in the MED nymphs, pupae, and adults ( $n d 4 l$ and atp 8 were excluded due to their short sequence length). Results showed that the expression level of individual mitochondrial genes varied between each developmental stage (Figure 7). We found that the atp 6 gene had the highest expression level in different development stages. At the adult stage, the expression level of the 11 PCGs displayed greater differences than that of the other two stages. In every stage, genes belonging to respiratory complex III and complex IV were expressed at higher levels than genes belonging to complex I. The same phenomenon existed in the early developmental stages of pig tissues [50]. Interestingly, mRNA levels not only differed among genes encoded by separate transcription units, but also showed significant differences among genes located in the same transcription unit (nd6 and cytb). The same phenomena were found in Drosophila and may be related to mRNA stability and post-transcriptional mechanisms [21].

\section{Discussion}

Next-generation sequencing is developing rapidly and many datasets have been generated in organisms whose mitochondrial genome is unknown [61]. However, many of the valuable RNA-seq datasets were not analyzed in details. In this study, we have demonstrated that to obtain the mitogenome (at least partially) based on existed RNA-seq data is possible. This strategy can be valuable for the cloning of mitogenomes from other non-model organisms with a sequenced transcriptome. For the B. tabaci complex, even though the mitogenome of New World species has been sequenced, we thought that utilizing Illumina sequence reads to obtain the MED mitogenome was more efficient. Because the mitogenomes of New World and MED species are quite diverged (about 20\%), some primers directly designed according to the mitochondrial sequence of New World species may not be used to clone MED genes. However, 
Table 4 The SNP sites in the complete mitogenome

\begin{tabular}{|c|c|c|c|c|c|c|c|}
\hline Pos & Ref & Alt & Gene_name & Strand & SNP_position_in_gene & Three_base_ref- $>$ three_base_alt & aa_ref- > aa_alt \\
\hline 984 & G & A & $\operatorname{cox} 1$ & + & 984 & ATG- $>$ ATA & $M->M$ \\
\hline 1873 & G & A & $\cos 2$ & + & 271 & GAA- $>$ AAA & $\mathrm{E}->\mathrm{K}$ \\
\hline 5020 & C & $\mathrm{T}$ & nd5 & - & 124 & GGA- > AGA & $G->S$ \\
\hline 7510 & C & $\mathrm{T}$ & cytb & + & 123 & GTC- $>$ GTT & $V->V$ \\
\hline 14675 & G & A & $n d 2$ & + & 198 & $A C G->A C A$ & $\mathrm{~T}->\mathrm{T}$ \\
\hline 14011 & A & G & CR region & & & & \\
\hline 14090 & G & A & $C R$ region & & & & \\
\hline 14180 & A & G & CR region & & & & \\
\hline
\end{tabular}

Pos: Site position in the complete mitogenome.

Ref: The base on mitochondrial sequence of MED.

Alt: The mutation base.

PCR primers can be designed according to the MED Illumina reads mapped to the New World mitogenome with nearly $100 \%$ confidence, therefore improve the probability of success (see Additional file 1). As many transcriptomes have been generated from different species, the transcriptome led approach is a useful way to extend existing data. In addition, this method may possibly be a solution or a guide for difficult to sequence mitogenomes.

The mitogenome of MED, which is the type species of the $B$. tabaci complex, shows similarities to the previously published mitogenome of the New World species. Both the mitogenomes have the identical set of genes in the same gene order with two putative control regions (Figure 1). However, the MED genome is slightly longer due to the presence of additional variable repeat sequences in the second control region. Codon usage differs between MED and New World mitogenomes. Overall, the MED mitogenome has $21.30 \%$ sequence divergence from that of the New World species, which is higher than the divergence at the cox1 barcode region (14.9\%). This is probably due to the fact that the $\operatorname{cox} 1$ sequences are more constrained than the other 12 PCGs and the presence of divergent noncoding regions (Table 2 and Figure 1). This finding is consistent with the previous claim that mitochondrial genes are susceptible to rapid evolution inferred from higher mutation rates and limited DNA repair mechanisms. The analysis of synonymous and nonsynonymous sites of PCGs between MED and New World showed that atp 8 was evolving under high selective pressure (Figure 2), whereas $\operatorname{cox} 1, \operatorname{cox} 2, \operatorname{cox} 3$ and atp 6 had the lowest substitution rates. This finding suggests that cox 1 , $\operatorname{cox} 2$, $\operatorname{cox} 3$, and atp 6 may be used for reconstructing evolutionary relationships at the species level, while atp 8 may be suitable for population level phylogenetic analysis.

EST data is important to define gene boundaries, predict processed mitochondrial transcripts and reveal transcription process of mitogenome. Mapping MED RNA-seq data to its mitogenome revealed a number of interesting characteristics about the MED mitogenome, such as gene expression, noncoding RNA, RNA polyadenylation and cistronic transcript. Noncoding RNAs play important roles in the splicing site recognition during the processing of transcripts if they have the ability to form stable stemloop structures [46,63]. Intergenic noncoding RNAs were found in the MED mitogenome. Previous RNA-seq analyses had revealed that a number of intergenic noncoding RNAs are expressed $[64,65]$ and noncoding RNAs appear to contain functional information [66], including transcription, RNA splicing, editing, translation and turnover [67]. UTRs and intronic regions flanking nuclear genes are critical for regulating its expression, but mitogenome lacks of these regions, indicating that the mitochondrial noncoding RNA may serve as a backup mechanism to coordinate gene expression [21]. Whether noncoding RNAs found in MED mitogenome have similar functions warrants further investigation. From the transcriptome data, $r r n L$ had the highest expression level. In Drosophila, the mitochondrial termination factor mTERF binds just downstream of the $3^{\prime}$ end of the ribosomal gene cluster and is responsible for the higher expression levels of rRNAs [68]. In New World mitogenome, the putative mTERF binding site (ACTAA) should locate in the noncoding DNA between $n d 1$ and tRNA-Ser, similar to Philaenus (AACTAT) which is the hemipteran and very similar to Lepidoptera [69]. In MED mitogenome, although there is no non-coding region between $n d 1$ and tRNA-Ser, the same consensus sequence (ACTAA) was discovered at the 3 ' end of $n d 1$. Interestingly, there are instances in beetles of frame shift mutations causing the mTERF site to become part of the coding region despite no changes to the sequence of the recognition site [70]. Therefore, we propose this region as the mTERF binding site in the MED mitogenome. Interestingly, the mTERF domain-containing protein 1-like and domain-containing protein 2-like were found in transctiptome data of MED 

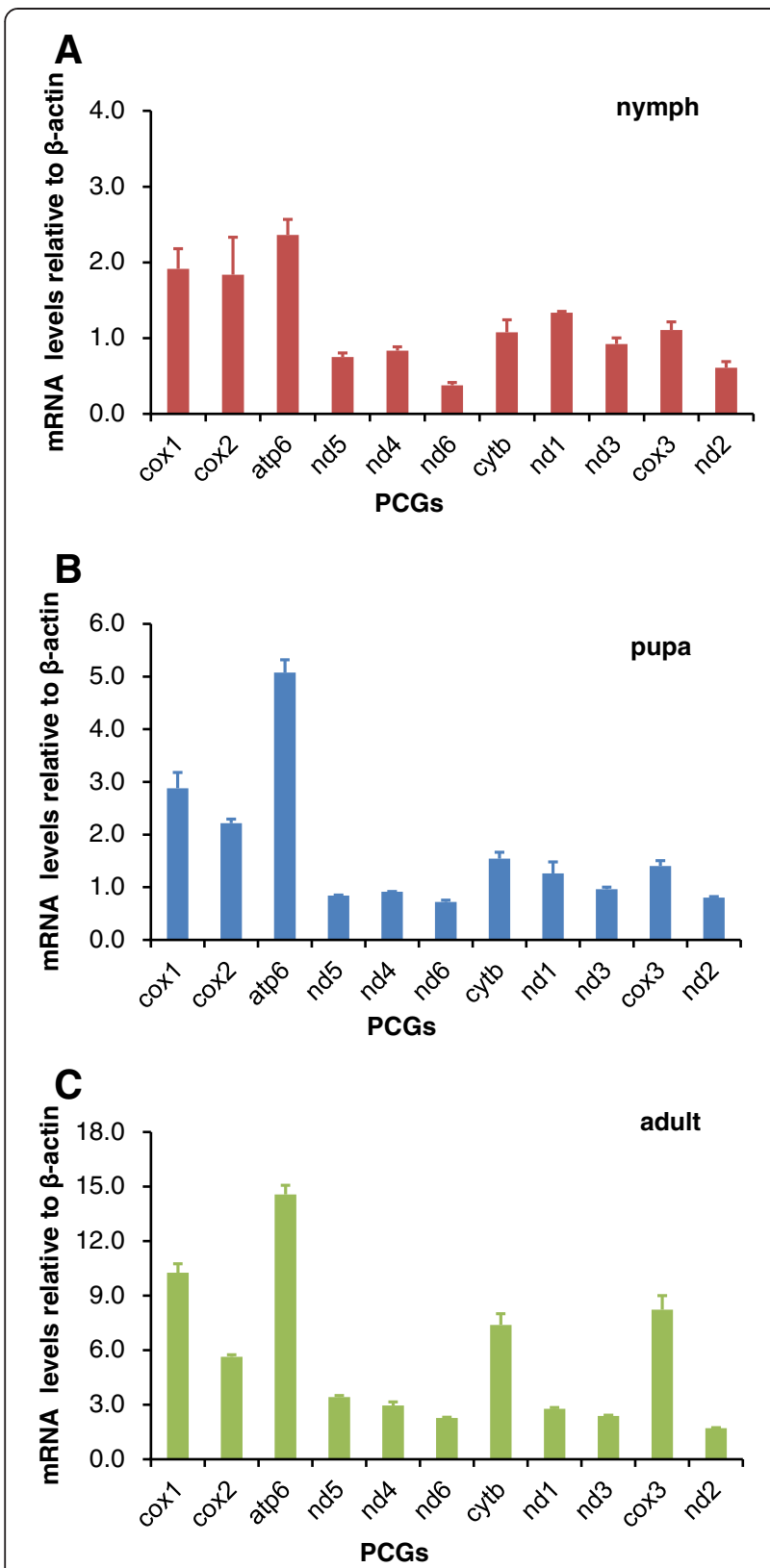

Figure 7 Expression levels of 11 PCGs in the nymph (A), pupa (B) and adult (C) of MED whiteflies. Real-Time PCR was used to detect genes expression levels. The $x$-axis shows the different PCGs, and the $y$-axis represents the mRNA expression level of different developing stages compared to each control ( $\beta$-actin).

(data unpublished). This further suggests that the mTERF binding site exists in the MED mitogenome.

In MED, atp $8 / 6$, nd4l/nd4 and nd6/cytb genes were found in the same dicistronic transcripts in mature mRNA. Generation of polycistronic transcripts is a common feature of many mitochondria and the co-transcription of genes is likely used for the regulation of gene expression [36]. Previous research has demonstrated that mRNAs that are smaller than $\sim 400$ nucleotides interact with $28 \mathrm{~S}$ subunit of the ribosome less readily than larger mRNAs and for efficient binding, thus a minimum transcript length of $\sim 400$ nucleotides is necessary [71,72]. This may partially explain why some mRNAs (i.e. $n d 4 l / n d 4$ and atp $8 / 6$ ) in the MED mitogenome are dicistronic. In these dicistronic mRNAs, both nad4l and atp8 are shorter than $\sim 400$ nucleotides. Therefore, both nad $4 l$ and atp 8 need to form a dicistronic mRNA with downstream genes to initiate the protein translation efficiently [71]. In dicistronic transcripts, the downstream gene lose the $5^{\prime}$ untranslated region, which are capable of forming extensive secondary structures and play important roles in post-transcriptional events [73-75]. In dicistronic transcripts of MED, absence of 5 ' untranslated regions of $a t p 6, n d 4$, cytb genes may increase the efficiency of translation, suggesting a different role for the persistence of dicistronic molecules [76]. Interestingly, for the dicistronic $n d 6 / c y t b$ and atp8/atp6 transcripts, poly(A) stretches were found in the 3' end of $n d 6$ and atp 8 genes. Similarly, in the tricistronic transcript (atp8/atp6/cox3) of Drosophila, poly(A) stretches were found in the 3 ' terminus of atp 8 and atp6, which suggest the variation in mitochondrial transcript cleavage events may occur in the insects [27,33]. Analyses of mitochondrial transcripts in additional species are needed to reveal the mechanism of the polycistronic processing in mitochondria.

The poly(A) tail has been identified to possibly contribute to translational control $[73,74]$ and mRNA degradation [75]. In this study, PCGs of the MED mitogenome were found to have varying lengths of poly(A) tails and some of the poly $(\mathrm{A})$ tails were critical to generate the UAA termination codon. Previous studies on mRNA polyadenylation concluded that the central sequence motif AAUAAA was essential for mRNA polyadenylation and 3' end formation, but recent studies of EST databases suggest that the frequency of the motif appeared low [76]. In our study, different possible poly(A) signals were also found in eight PCGs of the MED mitogenome.

\section{Conclusions}

In summary, the mitogenome of the invasive B. tabaci MED species contains the same gene rearrangement as that of the New World species. Using transcriptome data, the expression profile and the termination location of some genes were determined. In addition, polyadenylation, polycistronic transcripts and SNPs were discovered in $B$. tabaci mitogenome for the first time. The results presented here also demonstrate that utilizing RNA-seq data to analyze gene expression characteristics of mitogenome is practical. The MED and New World mitogenomes are interesting but the real utility of the sequence data comes from a comparative approach and it is our recommendation to sequence all of the mitogenomes for the species. With the inclusion of additional mitogenomes, patterns of mitochondrial gene expression 
and differences of energy usage in invasive and indigenous species could be tested.

\section{Methods}

\section{Mitogenome sequence mapping and assembly}

The complete mitogenome sequence of the New World species of B. tabaci was downloaded from GenBank: AY 521259 and was used as reference for alignment. MED transcriptome reads were directly mapped onto the New World mitogenome using Blastn [77]. As the mitogenome of New World and MED differ, when reads of MED were mapped to the New World mitogenome two mismatches were allowed. Then, reads mapped to the New World mitogenome were collected and assembled. Based on the position and sequence information of the assembled contigs, PCR primers were designed to complete the mitogenome sequence of MED (Additional file 2).

\section{PCR amplification, cloning and sequencing}

The method of obtaining MED whitefly DNA samples was described in Wang et al. [78]. Total genomic DNA of multiple individuals was isolated using the DNeasy animal tissue kit (Qiagen, Germany) following the manufacturer's protocol. PCR was carried out in an S1000 Thermal Cycler (Bio-Rad). A $25 \mu \mathrm{L}$ PCR reaction contained $0.5 \mu \mathrm{L}$ $10 \mu \mathrm{mol}$ primers, $2.5 \mu \mathrm{L} 10 \times$ PCR buffer, $2.0 \mu \mathrm{L} 10 \mathrm{mM}$ dNTP, $0.4 \mu \mathrm{L}$ LA Taq polymerase (Takara, Japan). Short PCRs $(<2.0 \mathrm{~kb})$ were carried out using Taq DNA polymerase (Takara, Japan) with the following PCR conditions: $95^{\circ} \mathrm{C}$ for $2 \mathrm{~min}$, followed by 35 cycles of $96^{\circ} \mathrm{C}$ for $30 \mathrm{~s}, 44-$ $52^{\circ} \mathrm{C}$ for $30 \mathrm{~s}, 72^{\circ} \mathrm{C}$ for $3 \mathrm{~min}$, as well as a final cycle of $72^{\circ} \mathrm{C}$ for $10 \mathrm{~min}$. Long PCRs were carried out using LA Taq DNA polymerase with the following PCR conditions: $95^{\circ} \mathrm{C}$ for $2 \mathrm{~min}$, followed by 35 cycles of $96^{\circ} \mathrm{C}$ for $30 \mathrm{~s}, 48$ $56^{\circ} \mathrm{C}$ for $30 \mathrm{~s}, 72^{\circ} \mathrm{C}$ for $3 \mathrm{~min}$ and a final cycle of $72^{\circ} \mathrm{C}$ for $10 \mathrm{~min}$. PCR fragments were purified and ligated into the pGEM-T Easy Vector (Promega, USA) and sequenced in both directions using the ABI BigDye 3.1 at GenScript (Nanjing, China).

\section{Annotation of the MED mitogenome}

DOGMA [79] was used to annotate the PCGs, rRNA genes of MED mitochondrial DNA. tRNAs were identified using tRNAscan-SE (invertebrate mitochondrial genetic code and 'mito/chloroplast' source) [80]. tRNA genes that could not be identified using tRNAscan-SE, sequences were aligned with published Aleyrodidae mitochondrial sequences (see below for species). BioEdit was used to calculate $\mathrm{A} / \mathrm{T}$ content and also to translate DNA into amino acids [81]. AT and GC skews were calculated by $(\mathrm{A}-\mathrm{T}) /(\mathrm{A}+\mathrm{T})$ and $(\mathrm{G}-\mathrm{C}) /(\mathrm{G}+\mathrm{C})$ respectively [29]. The complete mitogenome of MED was deposited in GenBank: JQ906700.

\section{Comparison of mitogenomes}

The numbers of synonymous substitutions (Ks) and nonsynonymous substitutions (Ka) for each gene were calculated with the software of DnaSP Version 5.10.01 [82,83]. For the sequence divergence analyses, pair-wise alignments were generated for all the 13 PCGs orthologous gene pairs based on protein sequences and DNA sequences using the MegaBlast algorithm. According to the mitochondrial codons, the divergence was determined for the contexts of nd, $4 \mathrm{~d}, \mathrm{CpG}$ and non-CpG sites [84]. The ratio of transitions over transversions $(\mathrm{Ts} / \mathrm{Tv})$ was caculated for the all coding region as well. The mitogenome sequences of Tetraleurodes acaciae (AY521626), Neomaskellia andropogonis (AY572539), Aleurochiton aceris (AY572538), Trialeurodes vaporariorum (AY521265), Aleurodicus dugesii (AY521251), Pachypsylla venusta (AY278317) and Schizaphis graminum (AY531391) were obtained from GenBank. The MED and New World partial cox1 sequences were extracted from GenBank AM176574 and AY057133, respectively.

\section{Mapping reads to the MED mitogenome, expression profiling and SNP analysis}

TopHat (Version:1.4.1) was used to align the MED NGS reads with the MED mitogenome with the following parameters: -g1 -r 200 -mate-std-dev20 -I 10000 [85]. The numbers of mapped reads for each gene were summed and divided by gene length to calculate the expression level of each mitochondrial gene. To detect polyadenylation, reads containing more than eight continuous $\mathrm{A}$ or $\mathrm{T}$ from the transcript data were aligned to the 13 mitochondrial genes using Blast. Reads that hit at or downstream of stop codons of PCGs were selected. Based on the mapping results, SAMTools (V0.1.13) were used to discovery the possible SNP sites with depth of at least 10 reads [86]. The analyses of amino acid mutation at PCGs and intergenic region were performed by a custom-written algorithm (available upon request) using mitochondrial codons.

\section{Verification of dicistronic transcripts}

The method of obtaining RNA from MED females had been described [36]. RNA was treated with DNase and 1st Strand cDNA was synthesized following the protocol of PrimeScript II 1st Strand cDNA Synthesis Kit (Takara). Three pairs of primers for the three dicistronic transcripts were designed respectively. PCR were performed with cDNA as template.

\section{qPCR analysis of PCG expression}

Total RNA was extracted from the three MED samples (nymph, pupa and adult) using SV total RNA isolation system (Promega) following the manufacturer's protocol [87]. The nymph sample include first- to third-instars. 
The SYBR ${ }^{\circ}$ Prime Script ${ }^{\text {tw }}$ RT-PCR Kit II (Takara) was used to synthesize cDNA and then qPCR was used to detect the expression of 11 mitochondrial genes. The ABI PRISM 7500 Fast Real-Time PCR System (Applied Biosystems) with SYBR-Green detection was employed to perform qPCRs. For normalization, $\beta$-actin was selected as the endogenous control. Every gene was analyzed three times and the relative expression levels were calculated by the $2^{-\Delta \Delta} \mathrm{Ct}$ method. As an endogenous control, the expression of $\beta$-actin was measured in parallel [88].

\section{Additional files}

Additional file 1: A diagram about our strategy to obtain the MED mitogenome sequence. The picture indicates how to get the complete MED mitogenome based on the transcriptome reads mapped to the New World mitogenome.

Additional file 2: Primers used to get the complete MED mitogenome. Additional file 3: Relative synonymous codon usage of the MED species. The frequency of synonymous codon (include stop codons) usage were shown.

Additional file 4: Relative synonymous codon usage of the New Worlds species. The frequency of synonymous codon (include stop codons) usage were shown.

Additional file 5: Start codons usage in nine different species. Start condons of 13 mitochondrial PCGs were shown. The 9 species are Bemisia tabaci (MED), B. tabaci (New World), Tetraleurodes acaciae, Neomaskellia andropogonis, Aleurochiton aceris, Trialeurodes vaporariorum, Aleurodicus dugesii, Pachypsylla venusta and Schizaphis graminum.

Additional file 6: Stop codon usage in 9 different species. Stop codons of 13 mitochondrial PCGs were shown. The 9 species are Bemisia tabaci (MED), B. tabaci (New World), Tetraleurodes acaciae, Neomaskellia andropogonis, Aleurochiton aceris, Trialeurodes vaporariorum, Aleurodicus dugesii, Pachypsylla venusta and Schizaphis graminum.

Additional file 7: The expression level of PCGs. By calculating the number of mapped reads, the expression level of 13 mitochondrial PCGs were revealed.

\section{Abbreviations}

cox1: Cytochrome oxidase, subunit I; cox2: Cytochrome oxidase, subunit II; atp8: ATP synthase, subunit 8; atp6: ATP synthase, subunit 6; nd5: NADH dehydrogenase, subunit 5; nd4: NADH dehydrogenase, subunit 4; nd4l: NADH dehydrogenase, subunit 4L; nd6: NADH dehydrogenase, subunit 6; cytb: Cytochrome b; nd1: NADH dehydrogenase, subunit 1; nd2: NADH dehydrogenase, subunit 2; nd3: NADH dehydrogenase, subunit 3; cox3: cytochrome oxidase, subunit III; nd2: NADH dehydrogenase, subunit 2; rrnS: Small subunit of mitochondrial ribosomal DNA; rrnL: Large subunit of mitochondrial ribosomal DNA.

\section{Competing interests}

The author(s) declare that they have no competing interests.

\section{Authors' contributions}

HLW, XWW and SSL conceived and designed the experimental plan. HLW and JY preformed the experiments. HLW, JY, LMB, QYZ, QL, XWW and SSL analyzed interpreted the sequence data. HLW, JY, LMB, XWW and SSL drafted the manuscript. All authors read and approved the final manuscript.

\section{Acknowledgments and funding information}

We thank Dr. Shu-Jun Wei and Dr. Xue-Xin Chen for advices on this research. This work was supported by the National Natural Science Foundation of China (grant number 31272104) and the National Basic Research Program of China (grant number 2009CB119203). A New Zealand-China Scientist Exchange Programme administered by The Royal Society of New Zealand and the Chinese Ministry and Science and Technology (MOST) funded LMB.

\section{Author details}

'Ministry of Agriculture Key Laboratory of Agricultural Entomology, Institute of Insect Sciences, Zhejiang University, Hangzhou 310058, China. ${ }^{2}$ ARC Centre of Excellence, Plant Energy Biology, The University of Western Australia, 35 Stirling Highway, Crawley 6009, Australia. ${ }^{3}$ The University of Queensland, Queensland Brain Institute, Brisbane, Qld 4072, Australia.

Received: 25 January 2013 Accepted: 12 June 2013

Published: 17 June 2013

\section{References}

1. Pimental D, Zuniga R, Morrison D: Update of the environmental and economics costs associated with alien-invasive species in the United States. Ecol Econ 2005, 52:273-288.

2. Inbar M, Gerling D: Plant-mediated interactions between whiteflies, herbivores, and natural enemies. Annu Rev Entomol 2008, 53:431-448.

3. Byrne DN, Bellows TS Jr: Whitefly biology. Ann Rev Entomol 1991, 36:431-457.

4. Brown JK: An update on the whitefly-transmitted geminiviruses in the Americas and the Caribbean Basin. FAO Plant Prot Bull 1990, 39:5-23.

5. Brown JK: Molecular markers for the identification and global tracking of whitefly vector-begomovirus complexes. Virus Res 2000, 71:233-260.

6. Hogenhout SA, Ammar ED, Whitfield AE, Redinbaugh MG: Insect vector interactions with persistently transmitted viruses. Annu Rev Phytopathol 2008, 46:327-359.

7. Boykin $L M$, Armstrong KF, Kubatko L, De Barro P: Species delimitation and global biosecurity. Evo Bioinform 2012, 8:1-37.

8. Hu J, De Barro P, Zhao H, Wang J, Nardi F, Liu SS: An extensive field survey combined with a phylogenetic analysis reveals rapid and widespread invasion of two alien whiteflies in China. PLoS One 2011, 6:e16061.

9. Sun $D B, X u J$, Luan JB, Liu SS: Reproductive incompatibility between the $B$ and $\mathrm{Q}$ biotypes of the whitefly Bemisia tabaci in China: genetic and behavioural evidence. Bull Entomol Res 2011, 101:211-220.

10. De Barro PJ, Liu SS, Boykin LM, Dinsdale AB: Bemisia tabaci: a statement of species status. Annu Rev Entomol 2011, 56:1-19.

11. Boykin LM, Shatters RG Jr, Rosell RC, McKenzie CL, Bagnall RA, De Barro P, Frohlich DR: Global relationships of Bemisia tabaci (Hemiptera: Aleyrodidae) revealed using Bayesian analysis of mitochondrial COI DNA sequences. Mol Phylogenet Evol 2007, 44:1306-1319.

12. Dinsdale A, Cook L, Riginos C, Buckley Y, Barro PD: Refined global analysis of Bemisia tabaci (Hemiptera: Sternorrhyncha: Aleyrodoidea: Aleyrodidae) mitochondrial cytochrome oxidase 1 to identify species level genetic boundaries. Ann Entomol Soc Am 2010, 103(2):196-208.

13. Tay WT, Evans GA, Boykin LM, De Barro PJ: Will the real Bemisia tabaci please stand up? PLOS One 2012, 7:e50550.

14. Thao ML, Baumann L, Baumann P: Organization of the mitochondrial genomes of whiteflies, aphids, and psyllids (Hemiptera, Sternorrhyncha). BMC Evol Biol 2004, 4:25.

15. Cameron SL, Lo N, Bourguignon T, Svenson GJ, Evans TA: A mitochondrial genome phylogeny of termites (Blattodea: Termitoidae): robust support for interfamilial relationships and molecular synapomorphies define major clades. Mol Phylogenet Evol 2012, 65:163-173.

16. Plazzi F, Ricci A, Passamonti M: The mitochondrial genome of Bacillus stick insects (Phasmatodea) and the phylogeny of orthopteroid insects. Mol Phylogenet Evol 2011, 58:304-316.

17. Nelson LA, Lambkin CL, Batterham P, Wallman JF, Dowton M, Whiting MF, Yeates DK, Cameron SL: Beyond barcoding: A mitochondrial genomics approach to molecular phylogenetics and diagnostics of blowflies (Diptera: Calliphoridae). Gene 2012, 511:131-142.

18. Ma C, Yang P, Jiang F, Chapuis MP, Shali Y, Sword GA, Kang L: Mitochondrial genomes reveal the global phylogeography and dispersal routes of the migratory locust. Mol Ecol 2012, 21:4344-4358.

19. Li D, Guo Y, Shao H, Tellier L, Wang J, Xiang Z, Xia Q: Genetic diversity, molecular phylogeny and selection evidence of the silkworm mitochondria implicated by complete resequencing of 41 genomes. BMC Evol Biol 2010, 10:81.

20. Ballard JWO: Comparative genomics of mitochondrial DNA in Drosophila simulans. J Mol Evol 2000, 51:64-75.

21. Torres TT, Dolezal M, Schloetterer C, Ottenwaelder B: Expression profiling of Drosophila mitochondrial genes via deep mRNA sequencing. Nucleic Acids Res 2009, 37:7509-7518. 
22. Reeve A, Lightowlers RN: An Introduction to Mitochondria. In Mitochondrial Dysfunction in Neurodegenerative Disorders. Edited by Reeve AK, Krishnan KJ, Duchen MR, Turnbull DM. London: Springer; 2012:3-18.

23. Shen $X$, Wang $H$, Ren J, Tian M, Wang M: The mitochondrial genome of Euphausia superba (Prydz Bay) (Crustacea: Malacostraca: Euphausiacea) reveals a novel gene arrangement and potential molecular markers. Mol Biol Rep 2010, 37:771-784.

24. Clary DO, Wolstenholme DR: The mitochondrial DNA molecule of Drosophila yakuba: nucleotide sequence, gene organization, and genetic code. J Mol Evol 1985, 22:252-271.

25. Cameron SL, Dowton M, Castro LR, Ruberu K, Whiting MF, Austin AD, Diement K, Stevens J: Mitochondrial genome organization and phylogeny of two vespid wasps. Genome 2008, 51:800-808.

26. Shao R, Campbell NJ, Schmidt ER, Barker SC: Increased rate of gene rearrangement in the mitochondrial genomes of three orders of hemipteroid insects. Mol Phylogenet Evol 2001, 18:1828-1832.

27. Stewart JB, Beckenbach AT: Characterization of mature mitochondrial transcripts in Drosophila, and the implications for the tRNA punctuation model in arthropods. Gene 2009, 445:49-57.

28. Costanzo MC, Fox TD: Control of mitochondrial gene expression in Saccharomyces cerevisiae. Annu Rev Genet 1990, 24:91-108.

29. Virbasius JV, Scarpulla RC: Activation of the human mitochondrial transcription factor A gene by nuclear respiratory factors: a potential regulatory link between nuclear and mitochondrial gene expression in organelle biogenesis. Proc Nat Acad Sci USA 1994, 91:1309-1313.

30. Perna NT, Kocher TD: Patterns of nucleotide composition at fourfold degenerate sites of animal mitochondrial genomes. J Mol Evol 1995, 41:353-358

31. Beckenbach AT, Stewart JB: Insect mitochondrial genomics 3: the complete mitochondrial genome sequences of representatives from two neuropteroid orders: a dobsonfly (order Megaloptera) and a giant lacewing and an owlfly (order Neuroptera). Genome 2009, 52:31-38.

32. Negrisolo E, Babbucci M, Patarnello T: The mitochondrial genome of the ascalaphid owlfly Libelloides macaronius and comparative evolutionary mitochondriomics of neuropterid insects. BMC Genomics 2011, 12:221.

33. Samuels AK, Weisrock DW, Smith JJ, France KJ, Walker JA, Putta S, Voss SR: Transcriptional and phylogenetic analysis of five complete ambystomatid salamander mitochondrial genomes. Gene 2005, 349:43-53.

34. Margam VM, Coates BS, Hellmich RL, Agunbiade T, Seufferheld MJ, Sun WL, Ba MN, Sanon A, Binso-Dabire CL, Baoua l, et al: Mitochondrial genome sequence and expression profiling for the Legume Pod Borer Maruca vitrata (Lepidoptera: Crambidae). PLoS One 2011, 6:e16444.

35. Nabholz B, Jarvis ED, Ellegren H: Obtaining mtDNA genomes from nextgeneration transcriptome sequencing: a case study on the basal Passerida (Aves: Passeriformes) phylogeny. Mol Phylogenet Evol 2010, 57:466-470

36. Wang XW, Luan JB, Li JM, Bao YY, Zhang CX, Liu SS: De novo characterization of a whitefly transcriptome and analysis of its gene expression during development. BMC Genomics 2010, 11:400.

37. Wolstenholme DR: Animal mitochondrial DNA: structure and evolution. Int Rev Cytol 1992, 141:173-216.

38. $\mathrm{Wu} \mathrm{Cl}$, Li WH: Evidence for higher rates of nucleotide substitution in rodents than in man. Proc Nat Acad Sci USA 1985, 82:1741-1745.

39. Hurst LD: The Ka/Ks ratio: diagnosing the form of sequence evolution. TIG 2002, 18:486.

40. Roques S, Fox CJ, Villasana MI, Rico C: The complete mitochondrial genome of the whiting, Merlangius merlangus and the haddock, Melanogrammus aeglefinus: a detailed genomic comparison among closely related species of the Gadidae family. Gene 2006, 383:12-23.

41. Yuan ML, Wei DD, Wang BJ, Dou W, Wang JJ: The complete mitochondrial genome of the citrus red mite Panonychus citri (Acari: Tetranychidae) high genome rearrangement and extremely truncated tRNAs. BMC Genomics 2010, 11:597.

42. Gullan P, Martin J: Sternorrhyncha (jumping plant-lice, whiteflies, aphids and scale insects). In Encyclopedia of Insects. Edited by Cardaé RT, Resh VH. New York: Academic Press/Elsevier Science; 2003:1079-1089.

43. Ojala D, Montoya J, Attardi G: Animal mitochondrial DNA: structure and evolution. Nature 1981, 290:470-474.

44. Coates BS, Sumerford DV, Hellmich RL, Lewis LC: Partial mitochondrial genome sequences of Ostrinia nubilalis and Ostrinia furnicalis. Int J Biol Sci 2005, 1:13-18.
45. Jiang WP, Li JL, Zheng RL, Wang GL: Analysis of complete mitochondrial genome of Cristaria plicata. Hereditas (Beijing) 2010, 32:153-162.

46. Li H, Liu H, Shi A, Štys P, Zhou X, Cai W: The complete mitochondrial genome and novel gene arrangement of the unique-headed bug stenopirates sp. (Hemiptera: Enicocephalidae). PLoS One 2012, 7:e29419.

47. Wei SJ, Shi M, Chen XX, Sharkey MJ, van Achterberg C, Ye GY, He JH: New views on strand asymmetry in insect mitochondrial genomes. PLOS One 2010, 5:e12708.

48. Saito S, Tamura K, Aotsuka T: Replication origin of mitochondrial DNA in insects. Genetics 2005, 171:1695-1705.

49. Brehm A, Harris D, Hernández M, Cabrera V, Larruga J, Pinto F, González A: Structure and evolution of the mitochondrial DNA complete control region in the Drosophila subobscura subgroup. Insect Mol Biol 2001, 10:573-578.

50. Karsten SA, Susanna C, Michael G, Merete F, Jan G: EST analysis on pig mitochondria reveal novel expression differences between developmental and adult tissues. BMC Genomics 2007, 8:367.

51. Ro S, Ma HY, Park C, Ortogero N, Song R, Hennig GW, Zheng H, Lin YM, Moro L, Hsieh JT: The mitochondrial genome encodes abundant small noncoding RNAs. Cell Res 2013, 23:759-774.

52. Nagaike T, Suzuki T, Katoh T, Ueda T: Human mitochondrial mRNAs are stabilized with polyadenylation regulated by mitochondria-specific poly (A) polymerase and polynucleotide phosphorylase. J Biol Chem 2005, 280:19721-19727.

53. Proudfoot $\mathrm{NJ}$ : Ending the message: poly (A) signals then and now. Gene Dev 2011, 25:1770-1782.

54. Barth C, Kennedy LA, Fisher PR: Mitochondrial gene expression and dysfunction in model Protozoa. In Organelle Genetics. Charpter 10. Edited by Bullerwell CE. Berlin Heidelberg: Springer; 2012:241-269.

55. Torres TT, Metta M, Ottenwälder B, Schlötterer C: Gene expression profiling by massively parallel sequencing. Genome Res 2008, 18:172-177.

56. Luikart G, England PR, Tallmon D, Jordan S, Taberlet P: The power and promise of population genomics: from genotyping to genome typing. Nat Rev Genet 2003, 4:981-994.

57. Barazzoni R, Short KR, Nair KS: Effects of aging on mitochondrial DNA copy number and cytochromec oxidase gene expression in rat skeletal muscle, liver, and heart. J Biol Chem 2000, 275:3343-3347.

58. Ammini CV, Hauswirth WW: Mitochondrial gene expression is regulated at the level of transcription during early embryogenesis of Xenopus laevis. J Biol Chem 1999, 274:6265-6271.

59. Zou S, Meadows S, Sharp L, Jan LY, Jan YN: Genome-wide study of aging and oxidative stress response in Drosophila melanogaster. Proc Natl Acad Sci USA 2000, 97:13726-13731.

60. Michel U, Stringaris AK, Nau R, Rieckmann P: Differential expression of sense and antisense transcripts of the mitochondrial DNA region coding for ATPase 6 in fetal and adult porcine brain: identification of novel unusually assembled mitochondrial RNAs. Biochem Biophy Res Commun 2000, 271:170-180.

61. Wang Z, Gerstein M, Snyder M: RNA-Seq: a revolutionary tool for transcriptomics. Nat Rev Genet 2009, 10:57-63.

62. Van Leeuwen $T$, Vanholme B, Van Pottelberge $S$, Van Nieuwenhuyse $P$, Nauen R, Tirry L, Denholm I: Mitochondrial heteroplasmy and the evolution of insecticide resistance: non-Mendelian inheritance in action. Proc Nat Acad Sci USA 2008, 105:5980-5985.

63. He Y, Jones J, Armstrong M, Lamberti F, Moens M: The mitochondrial genome of Xiphinema americanum sensu stricto (Nematoda : Enoplea): Considerable economization in the length and structural features of encoded genes. J Mol Evol 2005, 61:819-833.

64. Lung B, Zemann A, Madej MJ, Schuelke M, Techritz S, Ruf S, Bock R, Huettenhofer $A$ : Identification of small non-coding RNAs from mitochondria and chloroplasts. Nucleic Acids Res 2006, 34:3842-3852.

65. Haas BJ, Zody MC: Advancing RNA-Seq analysis. Nat Biotechnol 2010, 28:421-423.

66. Mattick JS: The genetic signatures of noncoding RNAs. PLoS Genet 2009, 5:e1000459.

67. Mattick JS, Makunin IV: Non-coding RNA. Hum Mol Genet 2006, 15(suppl 1):R17-R29.

68. Roberti M, Polosa PL, Bruni F, Musicco C, Gadaleta MN, Cantatore P: DmTTF, a novel mitochondrial transcription termination factor that recognises two sequences of Drosophila melanogaster mitochondrial DNA. Nucleic Acids Res 2003, 31:1597-1604.

69. Cameron SL, Whiting MF: The complete mitochondrial genome of the tobacco hornworm, Manduca sexta, (Insecta: Lepidoptera: Sphingidae), 
and an examination of mitochondrial gene variability within butterflies and moths. Gene 2008, 408:112-123.

70. Sheffield N, Song H, Cameron S, Whiting M: A comparative analysis of mitochondrial genomes in Coleoptera (Arthropoda: Insecta) and genome descriptions of six new beetles. Mol Biol Evol 2008, 25:2499-2509.

71. Liao $H$, Spremulli L: Effects of length and mRNA secondary structure on the interaction of bovine mitochondrial ribosomes with messenger RNA. J Biol Chem 1990, 265:11761-11765.

72. Liao H, Spremulli L: Interaction of bovine mitochondrial ribosomes with messenger RNA. J Biol Chem 1989, 264:7518-7522.

73. Banerjee A: 5 '-terminal cap structure in eucaryotic messenger ribonucleic acids. Microbiol Rev 1980, 44:175.

74. Proudfoot NJ, Furger A, Dye MJ: Integrating mRNA processing with transcription. Cell 2002, 108:501-512.

75. Denslow ND, Michaels GS, Montoya J, Attardi G, O'Brien TW: Mechanism of mRNA binding to bovine mitochondrial ribosomes. J Biol Chem 1989, 264:8328-8338.

76. Taanman JW: The mitochondrial genome: structure, transcription, translation and replication. Biochim Biophys Acta Bioenerg 1999, 1410:103-124.

77. Altschul SF, Gish W, Miller W, Myers EW, Lipman DJ: Basic local alignment search tool. J Mol Biol 1990, 215:403-410.

78. Wang XW, Luan JB, Li JM, Su YL, Xia J, Liu SS: Transcriptome analysis and comparison reveal divergence between two invasive whitefly cryptic species. BMC Genomics 2011, 12:458.

79. Wyman SK, Jansen RK, Boore JL: Automatic annotation of organellar genomes with DOGMA. Bioinformatics 2004, 20:3252-3255.

80. Lowe TM, Eddy SR: tRNAscan-SE: a program for improved detection of transfer RNA genes in genomic sequence. Nucleic Acids Res 1997, 25:955-964.

81. Hall TA: BioEdit: A user-friendly biological sequence alignment editor and analysis program for Windows 95/98/NT. Nucleic Acids Symp Ser 1999, 41:95-98.

82. Librado P, Rozas J: DnaSP v5: a software for comprehensive analysis of DNA polymorphism data. Bioinformatics 2009, 25:1451-1452.

83. Rozas J, Sanchez-DelBarrio JC, Messeguer X, Rozas R: DnaSP, DNA polymorphism analyses by the coalescent and other methods. Bioinformatics 2003, 19:2496-2497.

84. Hellmann I, Zöllner S, Enard W, Ebersberger I, Nickel B, Pääbo S: Selection on human genes as revealed by comparisons to chimpanzee CDNA. Genome Res 2003, 13:831-837.

85. Trapnell C, Pachter L, Salzberg SL: TopHat: discovering splice junctions with RNA-Seq. Bioinformatics 2009, 25:1105-1111.

86. Li H, Handsaker B, Wysoker A, Fennell T, Ruan J, Homer N, Marth G, Abecasis G, Durbin R: The sequence alignment/map format and SAMtools. Bioinformatics 2009, 25:2078-2079.

87. Li JM, Ruan YM, Li FF, Liu SS, Wang XW: Gene expression profiling of the whitefly (Bemisia tabaci) Middle East - Asia Minor 1 feeding on healthy and Tomato yellow leaf curl China virus-infected tobacco. Insect Sci 2011, 18:11-22.

88. Luan JB, Li JM, Varela N, Wang YL, Li FF, Bao YY, Zhang CX, Liu SS, Wang XW: Global analysis of the transcriptional response of whitefly to Tomato yellow leaf curl China virus reveals the relationship of coevolved adaptations. J Virol 2011, 85:3330-3340.

\section{Submit your next manuscript to BioMed Central and take full advantage of:}

- Convenient online submission

- Thorough peer review

- No space constraints or color figure charges

- Immediate publication on acceptance

- Inclusion in PubMed, CAS, Scopus and Google Scholar

- Research which is freely available for redistribution 